\title{
Cost and Emissions Implications of Coupling Wind and Solar Power
}

\author{
Seth Blumsack, Kelsey Richardson \\ John and Willie Leone Family Department of Energy and Mineral Engineering, Pennsylvania State University, University Park, \\ USA. \\ Email: blumsack@psu.edu
}

Received July $11^{\text {th }}, 2012$; revised August 22 ${ }^{\text {nd }}, 2012$; accepted August $30^{\text {th }}, 2012$

\begin{abstract}
We assess the implications on long-run average energy production costs and emissions of $\mathrm{CO}_{2}$ and some criteria pollutants from coupling wind, solar and natural gas generation sources. We utilize five-minute meteorological data from a US location that has been estimated to have both high-quality wind and solar resources, to simulate production of a coupled generation system that produces a constant amount of electric energy. The natural gas turbine is utilized to provide fill-in energy for the coupled wind/solar system, and is compared to a base case where the gas turbine produces a constant power output. We assess the impacts on variability of coupled wind and solar over multiple time scales, and compare this variability with regional demand in a nearby load center, and find that coupling wind and solar does decrease variability of output. The cost analysis found that wind energy with gas back-up has a lower levelized cost of energy than using gas energy alone, resulting in production savings. Adding solar energy to the coupled system increases levelized cost of energy production; this cost is not made up by any reductions in emissions costs.
\end{abstract}

Keywords: Wind Energy; Solar Energy; Air Emissions

\section{Introduction}

The integration of renewable electric generation resources, particularly solar and wind, into existing energy production and delivery systems, is considered to be a major technical and economic challenge. Variability of both wind and solar resources introduces additional stochastic components to the operational objective of balancing supply and demand across power control areas on a real-time basis; and presents planning challenges to system operators and generating companies that must make investment portfolio decisions to accommodate increased renewable energy penetration. Integration costs are expected to rise along with penetration levels, with recent reports suggesting costs of $\$ 2 / \mathrm{MWh}$ to $\$ 9 / \mathrm{MWh}$ [1] once wind penetration reaches $20 \%$ [2].

A number of different operational strategies are possible to achieve large-scale penetration of wind and solar energy. One such strategy would expand the use of frequency regulation and balancing energy services to compensate for unforecasted deviations in wind and solar power output. These so-called ancillary services are currently utilized in large-scale electricity systems to balance unexpected deviations in the supply-demand balance caused by volatile electricity demand or unplanned outages at generation or transmission assets. Such ancil- lary services can be provided on the supply side or the demand side. While system operators are experienced in procuring and dispatching ancillary services to handle fluctuations in the supply-demand balance, it is less clear whether existing ancillary services, and the various types of markets through which they are procured, are adequate to support the large-scale integration of wind and solar resources while maintaining high reliability and reasonable costs [3].

Wind and solar resources could also self-provide balancing energy by coupling their output with a controllable resource to provide a firm energy schedule to the system operator. The controllable resource essentially provides some amount of "fill-in" power to compensate for the variable resource. This coupling could be contractual, in which the wind or solar resource signs a physical energy purchase contract with a complementary resource; or the coupling could occur through horizontal integration, where a single generation operator manages the output of the variable and controllable resource to provide the firm energy schedule. The provision of fill-in power for wind turbines has been studied for hydroelectric dams [3], compressed air energy storage [4], and hybrid fill-in systems consisting of natural gas turbines that compensate for "slow" fluctuations and battery en- 
ergy storage that compensate for "fast" energy storage [5].

The increased use of ancillary services versus the coupling of variable and controllable resources is an unsettled topic in the electric utility industry and in the relevant research literature. We choose to assess the direct coupling of variable and controllable resources; in particular we assess how coupling multiple variableresources affects the utilization of the controllable resource. Specifically, we compare the costs and emissions of two coupled energy systems with a base-case system featureing a natural gas combustion turbine that produces a constant amount of electric energy. For comparison, we couple the natural gas turbine with an equivalently-sized wind energy installation; as well as coupling the gas turbine with a wind energy installation and a solar photovoltaic installation. Differences in the diurnal cycles of wind and solar energy [3] suggest that coupling these two variable sources may reduce the utilization of the controllable (and polluting) energy resource, with concomitant benefits in terms of air emissions.

The remainder of the paper discusses our data sources, modeling strategy and results. Section 2 outlines the data we have obtained for a high-quality wind and solar site in western Oklahoma, and describes how we estimate wind and solar production based on meteorological data. Technology and emissions costs are also discussed in Section 2. Section 3 contains the results of our modeling exercise, and Section 4 offers some discussion and conclusions.

\section{Data and Modeling}

Our case study is based on simulation of a coupled system of wind, solar and natural gas installed in Weatherford, in western Oklahoma. Weatherford is considered an advantageous location for such a coupled system since it is located in a high-quality wind zone (Class IV wind site [6]) and has relatively high-quality photovoltaic potential (based on analysis in [7]). We collect five-minute meteorological data for the Weatherford location from the Oklahoma Mesonet, a collection of over one hundred measurement stations across Oklahoma. Data available through the Mesonet includes averages of five-minute wind speed $(\mathrm{m} / \mathrm{s})$, wind direction, average solar radiation $\left(\mathrm{W} / \mathrm{m}^{2}\right)$, and other weather variables. Data are recorded at a height of $10 \mathrm{~m}$. We use 2002 as our study year, since that year is considered to be a historically average wind and solar irradiance year for Oklahoma.

\subsection{Wind Power Modeling}

Five-minute wind speed data at $10 \mathrm{~m}$ are converted to 80 $\mathrm{m}$ hub height data using the power-law equation:

$$
V_{2, t}=V_{1, t}\left(H_{2} / H_{1}\right)^{1 / 7},
$$

where $V_{1, t}$ and $V_{2, t}$ are the recorded and estimated wind speeds (m/s) at time interval $t$, at heights $H_{1}$ and $H_{2}$ (so in our case, $H_{1}=10 \mathrm{~m}$ and $H_{2}=80 \mathrm{~m} ; V_{1, t}$ represents the time series of wind speeds that we obtained from the Oklahoma Mesonet; and $V_{2, t}$ represents the estimated time series of wind speeds). As a robustness check, we generated estimated wind speeds using the roughness equation:

$$
V_{2, t}=V_{1, t}\left\{\ln \left(H_{2} / l\right) / \ln \left(H_{1} / l\right)\right\},
$$

where $l$ is the roughness length. We do not have explicit data on the roughness length for our location in Weatherford, although estimated wind speeds using a roughness length of 0.03 (corresponding to open and largely flat agricultural area) did not significantly differ from those estimated using the power-law equation in (1).

Finally, we converted our estimated wind speed data at a hub height of $80 \mathrm{~m}$ to wind power data using a power curve for a GE 1.5SL turbine; the power curve was obtained from Idaho National Laboratory data [8], and is shown in Figure 1. We note here that since our original Mesonet wind speed data are five-minute averages, our power calculations should be taken to represent average power within any given five minute interval.

Based on our simulated wind power production data, we calculated average energy (kWh) produced by a single turbine during each five minute interval for the Weatherford location. We calculated an annual capacity factor of 0.4 for the Weatherford wind site, based on five-minute data. Variation of estimated wind power production over several cycle lengths is shown in Figure 2, in terms of standard deviation of output and volatility (percentage standard deviation); the results are broadly consistent with previous analyses of the power spectral density of wind turbine outputs $[8,9]$.

To examine the correlation between estimated wind energy output at Weatherford and electricity demand in Oklahoma, we obtained hourly electricity demand data for Oklahoma Gas and Electric (OGE) and Oklahoma Municipal Power Authority from FERC Form 714 [10]. While OGE and OMPA are not the only electric utilities in Oklahoma, data from other Oklahoma utilities was not available for our analysis. A complete data set of hourly electricity demand in Oklahoma is not vital for our analysis, since we are primarily concerned with the relative variation in demand compared to wind and solar energy production.

We normalized both hourly wind production and hourly electricity demand for OGE and OMPA on a seasonal basis; this normalized data is shown in Figure 3. The annual correlation between wind production and electricity demand, based on analysis of the five-minute 




Figure 1. Wind power curve for the GE 1.5SL turbine.

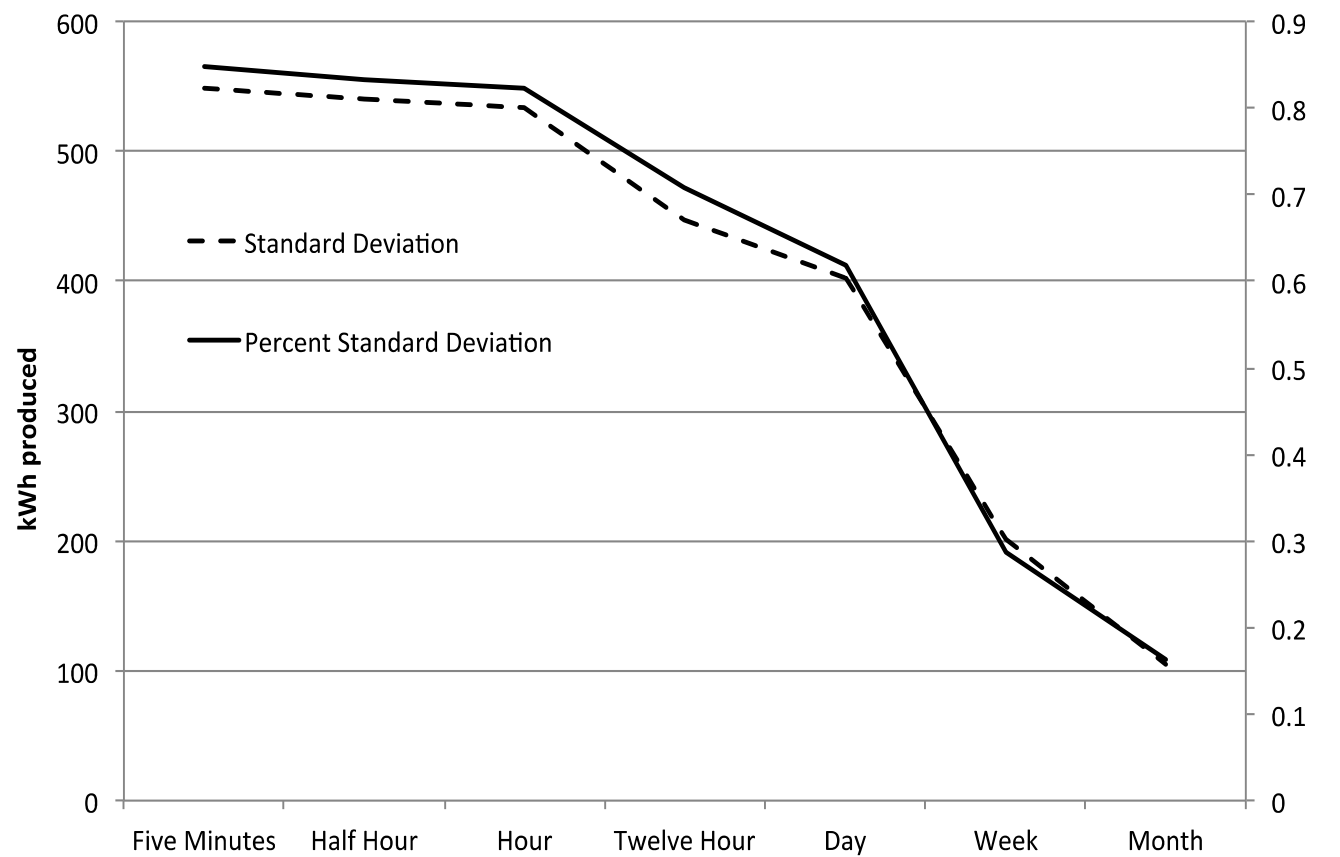

Figure 2. Variation in energy production (kWh, left axis) and percentage variation in production (volatility, right axis) for the simulated wind site in Weatherford.

data, is 0.061 . We note that unlike analyses of wind energy production and electricity consumption in other areas of the US $[3,11]$, there is a small but positive degree of correlation between our estimates of wind energy production in Weatherford and electricity consumption in portions of Oklahoma. We also observe more diurnal variability, on average, during the summer months than during other times of the year.

\subsection{Solar Production Modeling}

Five minute solar radiation data $\left(\mathrm{W} / \mathrm{m}^{2}\right)$ are utilized along with TRNSYS, an energy simulation program, to simulate photovoltaic energy production in Weatherford ${ }^{1}$. We assume a flat-plate fixed-axis collector with tracking,

${ }^{1}$ More information on TRNSYS is available at http://www.trnsys.com. We thank Rebecca Hott for assistance with TRNSYS modeling. 

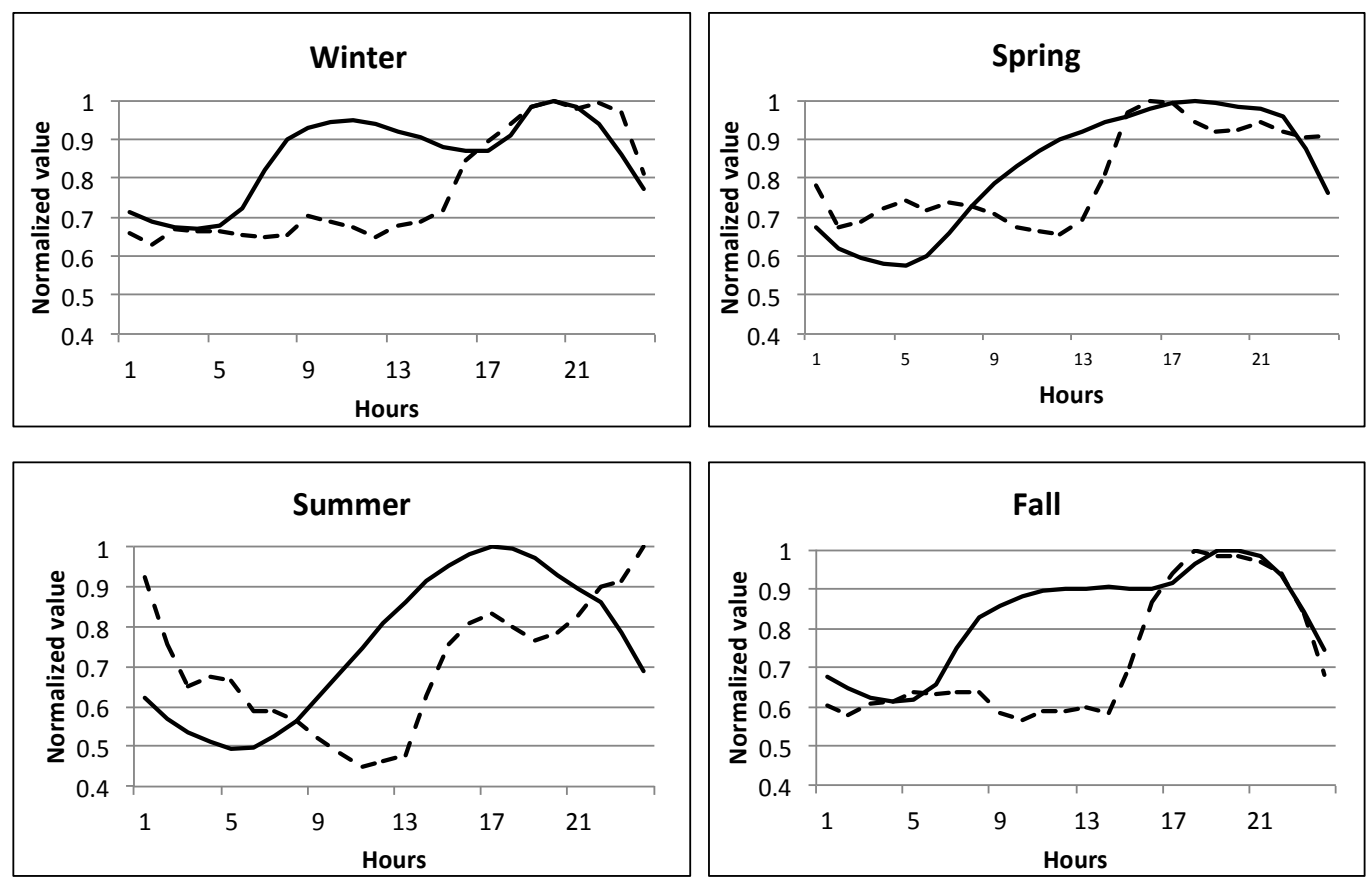

Demand

- - - - Wind Production

Figure 3. Normalized average wind production at Weatherford and electricity demand in the OGE and OMPA service territories.

and a conversion efficiency of $15 \%$. A variety of factors affect the production of energy from photovoltaic modules apart from the level of solar irradiance including dust and haze. We utilized detailed meteorological data from the ASOS station at Stafford Airport, a short distance east of our measurement station for Weatherford to incorporate the impacts of dust on solar energy production. The simulated photovoltaic installation has an estimated capacity factor of 0.17 .

We compared normalized photovoltaic energy production with normalized electricity demand and wind energy production by season, as shown in Figure 4. We observe the typical seasonal variations in photovoltaic production, with an extended period of peak photovoltaic production in the summer compared to other seasons. Graphically, we do not observe anti-correlation between wind and solar production of a particularly large magnitude; the seasonal correlations between wind and solar production for our case study are 0.27 in the wintertime, 0.2 in the spring, 0.21 in the summer and 0.21 in the fall.

\subsection{Natural Gas Production Modeling}

The natural gas turbine that we use in our analysis is a GE 10-1 combustion turbine with a nameplate capacity of $10 \mathrm{MW}$ and a combustion efficiency of $31.4 \%^{2}$ at the

\footnotetext{
${ }^{2}$ Turbine performance data was obtained from

http://www.gepower.com/businesses/ge_oilandgas/en/prod_serv/prod/g as_turbine/en/ge10_1.htm.
}

time of this writing, the price of natural gas in Oklahoma was \$6.96 per million BTU [12], implying a marginal energy cost of production of $\$ 75.63$ per MWh. A heat rate curve for this specific turbine was not available, so we use the quadratic emissions model described in [13] to estimate emissions of $\mathrm{NO}_{\mathrm{x}}$ and $\mathrm{CO}_{2}$ as a function of the magnitude and speed with which production at the gas turbine is ramped up and down in response to fluctuations in solar and energy resource availability. While the method in [13] has been criticized [14], it seems appropriate given the scale of our problem (i.e., powerplant level operations).

\subsection{Long Run Average Cost}

The Levelized Cost of Electricity (LCOE, units of $\$ / \mathrm{MWh}$ ) represents the long-run average cost of a power plant. We use the LCOE metric to compare the costs of a natural gas turbine with the costs of two coupled generation installations. The first system couples output from a wind installation with the gas turbine, while the second couples output from wind and photovoltaic installations with the gas turbine. The LCOE measures the average price required to break even over the long run-i.e., to recover the present discounted value of all capital and operating costs. The LCOE is defined as [15]:

$$
\mathrm{LCOE}=\left\{(r \times F C) / 1-e^{-r t}\right\} / c f+V C,
$$



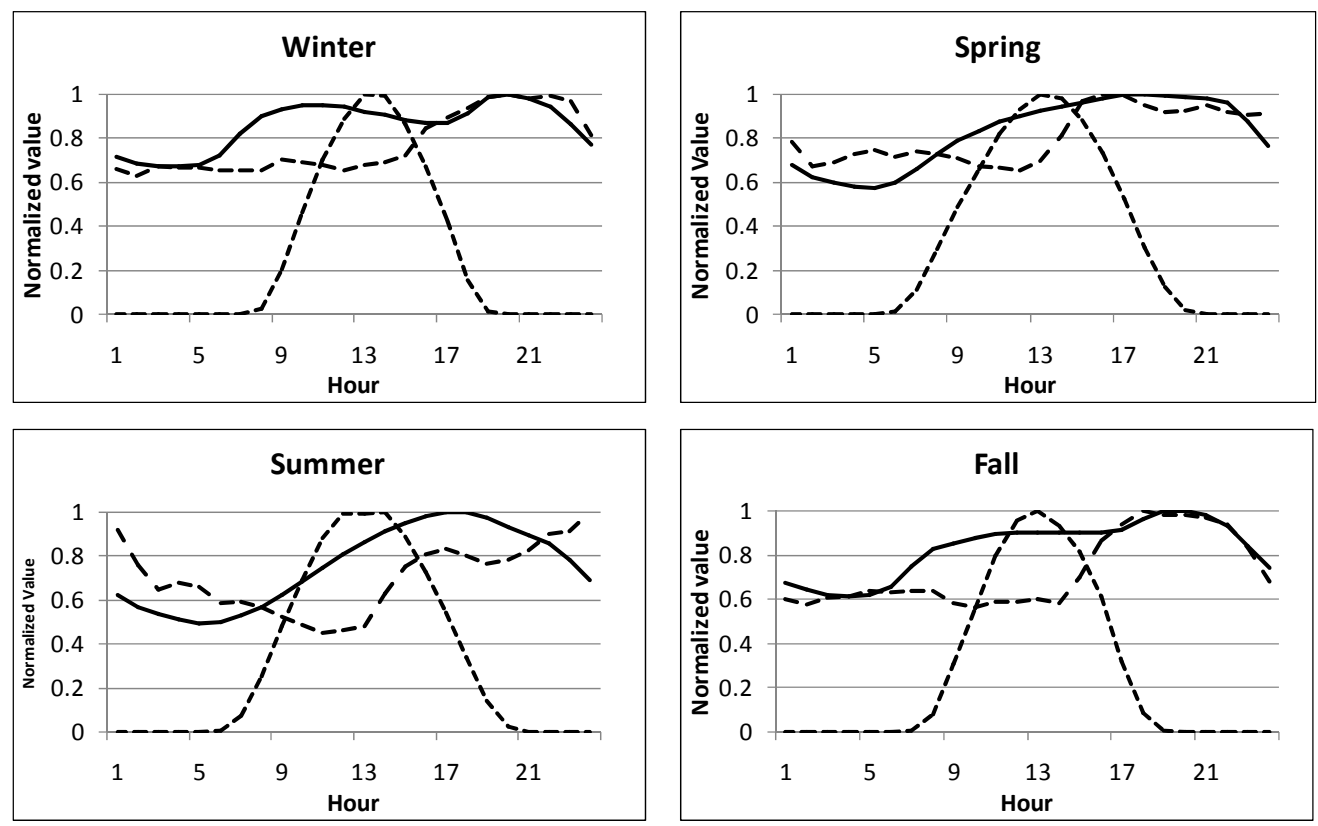

-Demand

- - - Wind Production

-------Solar Production

Figure 4. Normalized average wind and solar energy production at Weatherford and electricity demand in the OGE and OMPA service territories.

where $r$ is the annual discount rate; FC represents overnight fixed costs, $T$ is the relevant time horizon for the project (assumed to be 20 years for all technologies), $c f$ is the project's capacity factor, and $V C$ is the variable cost of producing a unit of energy. We assume that the overnight fixed costs are $\$ 500 / \mathrm{kW}$ for the natural gas plant [16], $\$ 2100 / \mathrm{kW}$ for the wind turbine [6] and $\$ 5000 / \mathrm{kW}$ for the photovoltaic installation [16].

\section{Results}

We simulate the operation of three systems producing a constant amount of power, and compare the cost and emissions implications $\left(\mathrm{CO}_{2}\right.$ and $\left.\mathrm{NO}_{\mathrm{x}}\right)$ of each. The three systems we consider in our analysis are a stand- alone gas combustion turbine; a coupled system of wind and natural gas; and a coupled system of wind, solar photovoltaic and natural gas. In the latter two scenarios, the gas turbine is utilized for providing fill-in power as described in Section 1. The cost and emissions implications are compared on a per-unit-energy basis, so we do not need to specify an explicit size for the system (although our capital cost figures in Section 2.4 implicitly assume utility-scale installations).

Given the capital and operating costs of the gas and wind turbines, and the high capacity factor of the modeled wind installation in Weatherford, the LCOE for the coupled wind/gas system is lower than for the gas system alone (\$86.59/MWh for the coupled system versus $\$ 95.60 / \mathrm{MWh}$ for the natural gas turbine alone). The
LCOE of the coupled system is naturally sensitive to fluctuations in the fuel price for the gas turbine and the availability of the wind turbine; if the price of natural gas were to drop below $\$ 6 / \mathrm{mmBTU}$ then the gas turbine alone would be more economical. Because of the high capital costs of solar photovoltaic, and the low capacity factor, we find that coupling photovoltaics with the wind/gas system increases the LCOE to \$223.24/MWh. Defining the integration cost for solar photovoltaics as the increase in (levelized) energy costs for each fiveminute interval for the wind/solar/gas system versus the wind/gas system, we see that average integration costs for including photovoltaics in a portfolio of wind and fossil energy vary seasonally and range from between \$57/MWh to nearly \$120/MWh (Figure 5).

Moreover, the emissions of $\mathrm{NO}_{\mathrm{x}}$ following the integration of photovoltaics into the wind/gas system increase for the scenario that we simulated, although $\mathrm{CO}_{2}$ emissions from the coupled system decline. Figure 6(a) shows that integrating wind and solar with the natural gas turbine reduces $\mathrm{CO}_{2}$ emissions by 500 to 1000 tonnes per month, assuming a system with $10 \mathrm{MW}$ of renewables and $10 \mathrm{MW}$ of natural gas turbine capacity. The incremental avoided emissions from coupling photovoltaics with the wind/gas system are relatively small, at 25 tonnes per month. Figure 6(b) shows $\mathrm{NO}_{\mathrm{x}}$ emissions from the three systems; coupling wind and solar with the natural gas turbine increases $\mathrm{NO}_{\mathrm{x}}$ emissions by a factor of between three and five, depending on the time of year. 


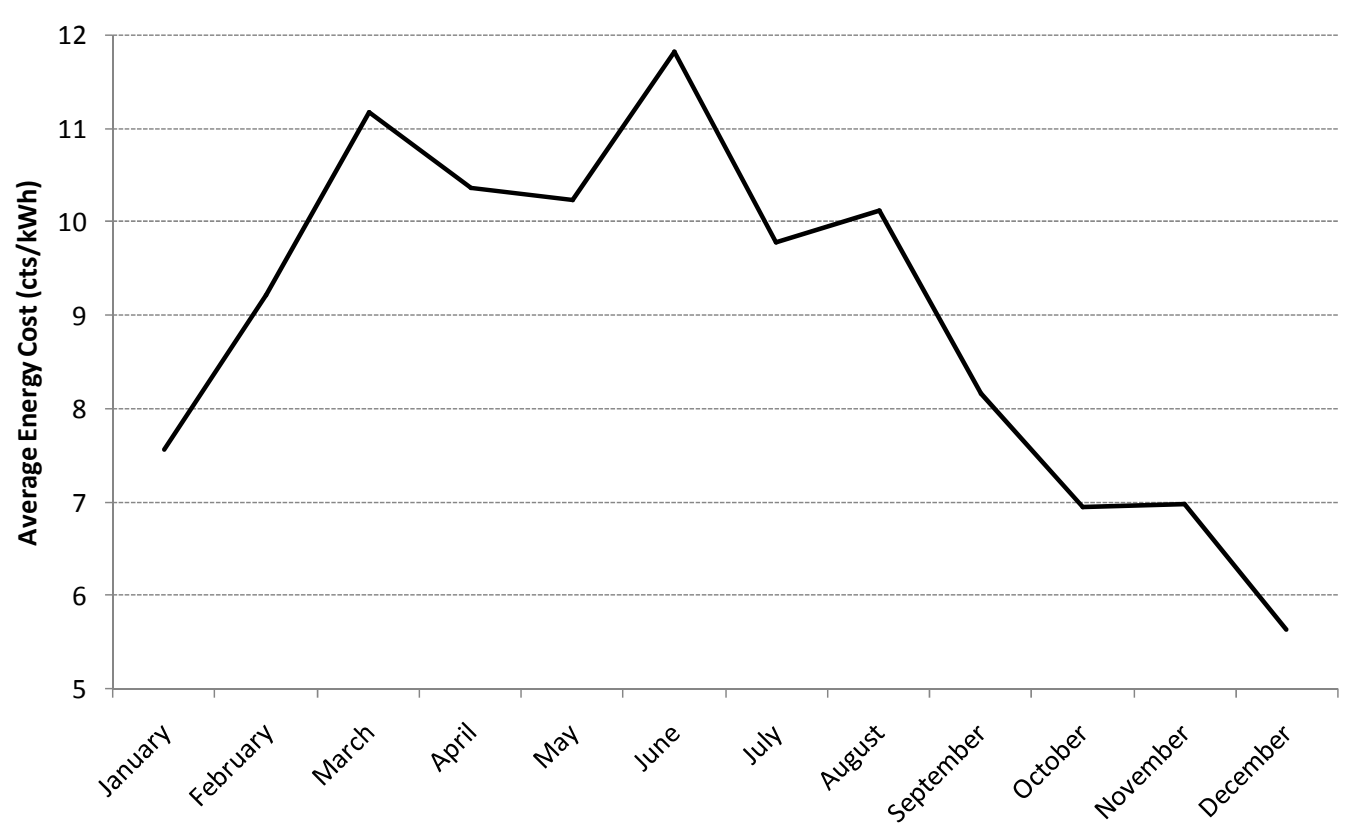

Figure 5. Average energy cost of integrating photovoltaics into the wind/gas portfolio.
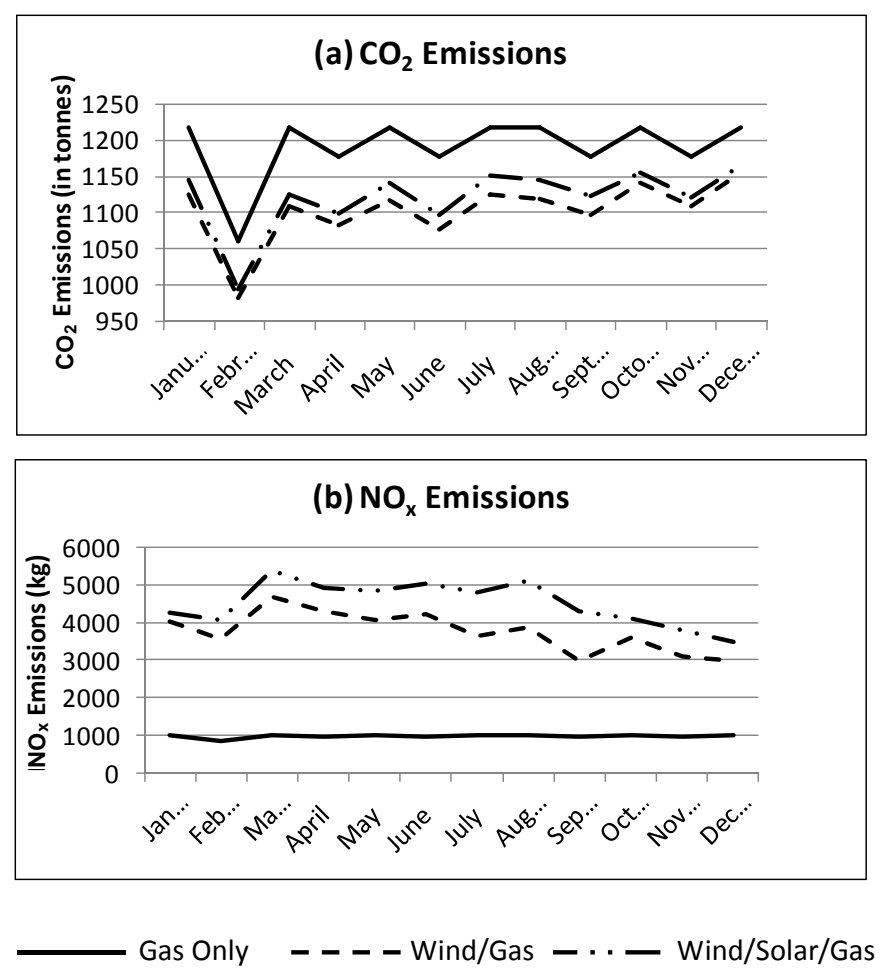

Figure 6. Emissions impacts from coupling wind and natural gas; and coupling wind, solar and natural gas. Panel (a) shows the decrease in $\mathrm{CO}_{2}$ emissions from coupling renewables and fossil fuels, while panel (b) shows the increase in $\mathrm{NO}_{\mathrm{x}}$ emissions.

\section{Discussion and Conclusions}

Our results on the emissions implications of coupling renewables and fossil fuels are consistent with previous research [13]. Coupling wind energy with a natural gas turbine can potentially reduce long-run average production costs, although incrementally adding photovoltaics to the portfolio increases costs. We find that the coupled wind/gas system has higher $\mathrm{NO}_{\mathrm{x}}$ emissions than simply running a natural gas turbine at a constant level of output, 


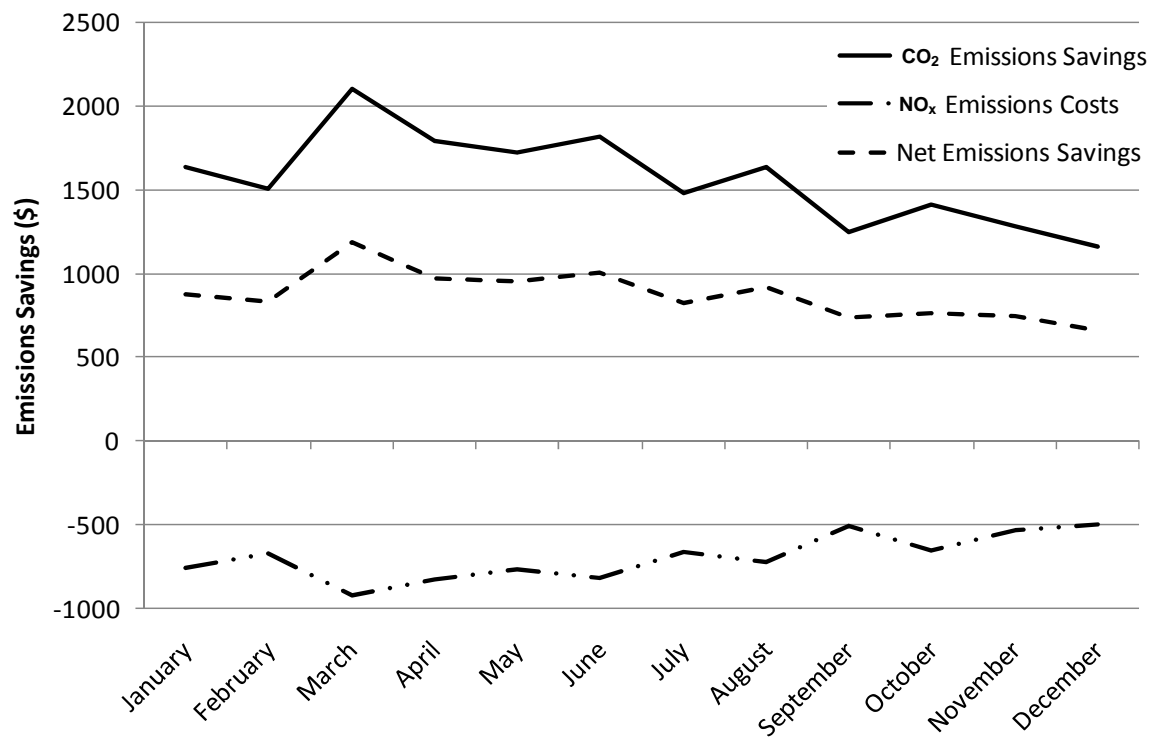

Figure 7. Monetary savings, including emissions costs, from coupling wind and natural gas. We do not find any monetary savings from adding photovoltaics to the wind/gas capacity portfolio.

but lower $\mathrm{CO}_{2}$ emissions. Adding photovoltaics reduces the $\mathrm{CO}_{2}$ emissions profile of the system slightly while increasing the $\mathrm{NO}_{\mathrm{x}}$ profile.

In a scenario where emissions are priced, the reduction in $\mathrm{CO}_{2}$ cost may outweigh the increase in $\mathrm{NO}_{\mathrm{x}}$ costs for the wind/gas coupled system, yielding net savings (compared to running the gas-only system) depending on the relative emissions prices. Using prevailing $\mathrm{CO}_{2}$ prices from the European Market of $\$ 22.60$ per tonne, and a $\mathrm{NO}_{\mathrm{x}}$ price of $\$ 0.25 / \mathrm{kg}$, we find that pricing emissions leads to additional net savings for the wind/gas coupled system (Figure 7). While there would be additional net emissions cost savings from adding photovoltaics to the coupled system, the savings are not sufficient to offset the higher long-run average production cost.

The incentives for owners of renewable energy projects to couple operations with controllable energy sources are still a matter of debate. In some territories that have adopted wholesale restructuring, such coupling would allow the owners to receive capacity payments. In territories where bilateral market activity is the dominant form of trade, coupled renewable and fossil projects may be able to sign "firm" energy contracts (subject to availability of transmission), which typically sell at a premium.

\section{Acknowledgements}

The authors would like to acknowledge support from the Wilson Endowment in the College of Earth and Mineral Sciences at Penn State for the purchase of Oklahoma Mesonet data; staff at the Oklahoma Mesonet project for assistance with the data; and Jeffrey Brownson and Re- becca Hott for advice on modeling solar energy production.

\section{REFERENCES}

[1] NREL, "Wind Technologies Market Report," 2010. www1.eere.energy.gov/wind/pdfs/51783.pdf

[2] US DOE, "20\% Wind Energy by 2030: Transmission and Integration into the US Electric System,” 2008. http://www.20percentwind.org/Final_DOE_Executive_Su mmary.pdf

[3] A. Fernandez, S. Blumsack and P. Reed, "Evaluating Wind-Following and Ecosystem Services for Hydroelectric Dams," Center for Research in Regulated Industries Eastern Conference, Skytop, May 2011.

[4] E. Fertig and J. Apt, "Economics of Compressed Air Energy Storage to Integrate Wind Power: A Case Study in ERCOT,” Energy Policy, Vol. 39, No. 5, 2011. pp. 23302342. doi:10.1016/j.enpol.2011.01.049

[5] E. Hittinger, J. Whitacre and J. Apt, "Compensating for Wind Variability Using Co-Located Natural Gas Generation and Energy Storage," Energy Systems, Vol. 1, No. 4, 2010, pp. 417-439. doi:10.1007/s12667-010-0017-2

[6] NREL, "Wind Energy Resource Atlas of the United States," Renewable Resource Data Center (RReDC) Home Page, 2002. http://rredc.nrel.gov/wind/pubs/atlas/appendix_A.html

[7] University of Oklahoma, Environmental Verification and Analysis Center. http://www.ocgi.okstate.edu/owpi/Oksolarmap.gif

[8] Idaho National Laboratory, "Wind Turbine Power Curve Data," 2012. http://www.inl.gov/wind/software/

[9] J. Apt, "The Spectrum of Power from Wind Turbines," Journal of Power Sources, Vol. 18, No. 2, 2007, pp. 369374. doi:10.1016/j.jpowsour.2007.02.077 
[10] FERC, “Form 714-Pre-Electronic Filing Data: 19932004,” Federal Energy Regulatory Commission, 2011. http://www.ferc.gov/docs-filing/forms/form-714/data.asp

[11] Carnegie Mellon Electricity Industry Center, “The Smart Grid: Sorting the Reality from the Hype,” 2009. http://www.cmu.edu/electricity

[12] Price data from US Energy Information Administration, 2012.

http://www.eia.gov/dnav/ng/ng_pri_sum_dcu_nus_m.htm

[13] W. Katzenstein and J. Apt, “Air Emissions Due to Wind and Solar Power," Environmental Science \& Technology, Vol. 43, No. 2, 2009, pp. 253-258. doi:10.1021/es801437t

[14] A. Mills, R. Wiser, M. Milligan and M. O’Malley, "Comment on 'Air Emissions Due to Wind and Solar Power', Environmental Science and Technology, Vol. 43, No. 15, 2009, pp. 6106-6107. doi:10.1021/es900831b

[15] S. Stoft, "Power System Economics: Designing Markets for Electricity,” Piscataway, IEEE, 2002.

[16] Energy Information Administration, "Updated Capital Cost Estimates for Electricity Generation Plants,” 2011. http://www.eia.gov/oiaf/beck_plantcosts/pdf/updatedplant costs.pdf 